OPEN ACCESS

Edited by:

Gurvinder Kaur,

All India Institute of Medical Sciences,

India

Reviewed by:

Jean Sylvia Marshall,

Dalhousie University, Canada

Tijana Martinov,

Fred Hutchinson Cancer Research

Center, United States

${ }^{*}$ Correspondence:

Niti Puri

purin@mail.jnu.ac.in

Specialty section:

This article was submitted to

Hematologic Malignancies,

a section of the journal

Frontiers in Oncology

Received: 26 June 2021 Accepted: 09 September 2021

Published: 24 September 2021

Citation:

Mehtani D and Puri N (2021) Steering Mast Cells or Their Mediators as a Prospective Novel Therapeutic Approach for the Treatment of Hematological Malignancies.

Front. Oncol. 11:731323. doi: 10.3389/fonc.2021.731323

\section{Steering Mast Cells or Their Mediators as a Prospective Novel Therapeutic Approach for the Treatment of Hematological Malignancies}

\author{
Deeksha Mehtani and Niti Puri * \\ Cellular and Molecular Immunology Lab, School of Life Sciences, Jawaharlal Nehru University, New Delhi, India
}

Tumor cells require signaling and close interaction with their microenvironment for their survival and proliferation. In the recent years, Mast cells have earned a greater importance for their presence and role in cancers. It is known that mast cells are attracted towards tumor microenvironment by secreted soluble chemotactic factors. Mast cells seem to exert a pro-tumorigenic role in hematological malignancies with a few exceptions where they showed anti-cancerous role. This dual role of mast cells in tumor growth and survival may be dependent on the intrinsic characteristics of the particular tumor, differences in tumor microenvironment according to tumor type, and the interactions and heterogeneity of mediators released by mast cells in the tumor microenvironment. In many studies, Mast cells and their mediators have been shown to affect tumor survival and growth, prognosis, inflammation, tumor vascularization and angiogenesis. Modulating mast cell accumulation, viability, activity and mediator release patterns may thus be important in controlling these malignancies. In this review, we emphasize on the role of mast cells in lymphoid malignancies and discuss strategies for targeting and steering mast cells or their mediators as a potential therapeutic approach for the treatment of these malignancies.

Keywords: hematological malignancy, mast cells, lymphoid neoplasms, lymphoma, leukemia, blood cancer, cancer therapeutics, myeloma

\section{INTRODUCTION}

Cancer is a complicated disease and a leading cause of mortalities, the world over. Hematological malignancies are the most common and frequently occurring cancers in children and the elderly ( 1 , 2). Development of these malignancies is characterized by a crucial transition of hematopoietic cells of a particular lineage to cancerous cells with altered and abnormal cellular proliferation. One such condition that is most commonly seen in elderly people is clonal hematopoiesis, a premalignant disorder characterized by aberrant proliferation of clonally-derived hematopoietic stem cells carrying somatic mutations in leukemia-related genes. Aside from age advancement, this phenomenon is more common in solid or lymphoid tumors and is linked to genotoxic stress (3). Leukemia refers to the clonal expansion of abnormal leukocyte cells in the bone marrow (BM), 
which leads to the elevated levels of affected cells in the blood circulation. While lymphoma or lymphoid malignancies show elevated numbers of $\mathrm{B}$ or $\mathrm{T}$ lymphocytes which are present as tumor in the lymphatic tissue (1). Due to their complexity, the hematologic malignancies become challenging to manage.

Cancer pathogenesis involves multiple interactions between neoplastic cells and their microenvironment resulting in maintenance and progression or rejection of growing tumor. For hematological malignancies, BM or secondary lymphoid organs form the cancer microenvironment which is composed of stromal cells, fibroblasts, immune cells and vascular endothelial cells (4). Dynamic signaling by soluble mediators or cell-cell interactions between leukemia or lymphoma cells and immune cells in the tumor or surrounding microenvironment strongly determines the malignant progression or eradication of tumor. Presence of immune cells also plays a greater role in tumor development or elimination. $\mathrm{CD}^{+} \mathrm{T}$ cells and NK cells eradicate immunogenic cancer cells which leave the variants of cells that are non-immunogenic, making it difficult for the immune system to recognize them (5). Many studies have associated the presence of Mast cells (MCs) and release of various mediators with the remodeling of tumor microenvironment.

MCs are innate immune granulocytes, derived from bone marrow, that migrate to peripheral tissues to mature and reside in mucosal layers and near blood vessels remaining close to the external environment so as to respond quickly to an invasion by a pathogen or allergen (6). Years ago, Paul Ehrlich discovered MCs and found them to be present in close proximity to a tumor (7). MCs have a wide range of surface receptors like FcéRI, histamine receptors, c-KIT receptor, Pattern recognition receptors (PRRs) which on activation make them capable of releasing diverse set of mediators in response to various stimuli (8). In tumor microenvironment, MCs release molecules like Vascular endothelial growth factor (VEGF), heparin, tryptase, Fibroblast growth factor (FGF-2) which can initiate tumor angiogenesis and molecules like Matrix metalloproteinases (MMP-9 and MMP-2) which can enable tumor niche remodeling, migration and invasiveness collectively leading to cancer progression (9). Whereas secreted molecules like histamine, IL-4, IL-8, Tumor necrosis factor (TNF- $\alpha$ ) contribute in inhibiting tumor cell survival or growth and inducing apoptosis (9). MC functions are extremely context-dependent and cross-talk between tumor cells-MCs and other tumor-associated immune cells are likely to play a role in determining whether a tumor will be eliminated or progressed.

The existing anti-cancerous treatments focus on targeting the mechanisms behind the abnormally proliferating cells. Therefore, an unmet need in cancer research is to understand the cancer microenvironment and the interplay between tumor cells and the immune cells like MCs which on activation release a diverse variety of mediators having capacity to modulate the tumor microenvironment in favor of or for rejection of cancer. In this review, we emphasize on the role of MCs in hematological malignancies and discuss the strategies to target and steer MCs or their mediators as a potential therapeutic approach for these malignancies.

\subsection{Dual Role of MCs in Hematological Malignancies}

The contribution of immune and inflammatory cells, such as MCs, is well known in the control, progression and invasion of malignant cells. Here we discuss the studies highlighting the correlation between the amount of tumor-infiltrating MCs and the extent of tumor aggressiveness and propagation, implying a significant role of MCs in various hematological malignancies. The characteristics of the studies reviewed have been compiled in Tables 1 and 2.

\subsubsection{The Role of Mast Cells in Lymphomas}

MCs have been documented to be involved in shaping the microenvironment in lymphomas, mostly by increasing the microvessel density, increasing angiogenesis and fibrosis thus leading to rogue advancement of lymphomas. Hodgkin's lymphoma (HL), derived from mature B cells, is characterized by tumor cells, Hodgkin's and Reed-Sternberg (HRS) cells in a smoldering inflammatory microenvironment (33). Abundance in tryptase positive MCs has been predominantly associated with inflammation and poor prognosis in patients with HL. Infiltration of TGF- $\beta$ producing MCs in HL's subtype-nodular sclerosis has been associated with the invasion of neoplastic cells, the development of fibrosis and progression of HL by the promotion of angiogenesis $(10,25)$. MCs were shown to promote HL cell growth in SCID mice in vivo (25). In HL, MCs have also been reported to interact directly with tumor cells via CD30-CD30L, causing HRS cells to become activated and proliferate could be important for HL pathogenesis (10-12). Indirect interactions between tumor cells and MCs caused by soluble factors produced by HRS cells, such as IL-9, IL-13, CCL5/RANTES are important for MC infiltration and proliferation $(10,11,13,26)$. MCs are, therefore, involved in shaping the HL microenvironment in terms of angiogenesis and fibrosis leading to advancement of tumor cells towards invasion and nodular progression.

Splenic marginal zone lymphoma (SMZL), is characterized by indolent neoplastic $B$ cells that infiltrate the spleen and sometimes the BM (34). MCs are directly recruited by neoplasm cells in the tumor microenvironment and support the stromal cell proliferation, angiogenesis, extracellular matrix (ECM) remodeling in this B cell malignancy. Also, stromal cells highly express CD40 which recruits MCs expressing CD40 ligand, lead to the release of IL- 6 with other pro-inflammatory cytokines, thereby activating $B$ cells, increasing the survival and proliferation of neoplastic cells and contributing to pathobiology of SMZL progression (14).

B cell lymphoma (BCL) accounts for $90 \%$ of lymphoid neoplasms worldwide. The most common and aggressive form of non-Hodgkin lymphoma that occurs within the lymph nodes, but can be present anywhere in the body outside the lymphoid system, is diffuse large B cell lymphoma (DLBCL). Marinaccio et al. speculated that a decrease in MC density would result in reduced inflammatory signals and increased pro-angiogenic signals by regulatory $\mathrm{T}$ cells $\left(\mathrm{T}_{\text {regs }}\right)(17)$. Whereas, an increase in $\mathrm{MC}$ density can enhance inflammation and suppress the functions of $T_{\text {regs }}$ thereby allowing the differentiation and expansion of $T_{h} 17$ lymphocytes leading to angiogenesis (17). 
TABLE 1 | Characteristics of clinical studies included in this review mentioning the stage of hematological malignancies and number of mast cells.

\begin{tabular}{|c|c|c|c|c|c|}
\hline $\begin{array}{l}\text { Type of } \\
\text { hematological } \\
\text { malignancy }\end{array}$ & Stage of hematological malignancy & Mast cell number & $\begin{array}{l}\text { Role } \\
\text { played by } \\
\text { MCs }\end{array}$ & $\begin{array}{c}\text { Year of } \\
\text { publication }\end{array}$ & Reference \\
\hline \multirow{2}{*}{$\begin{array}{l}\text { Hodgkin's } \\
\text { Lymphoma }\end{array}$} & $\begin{array}{l}\text { Stage I-IIA } \\
\text { Stage IIB-IV }\end{array}$ & $\begin{array}{l}\text { The disease-free survival rate and overall survival rate were } \\
\text { both lower in patients with a higher MC count }\end{array}$ & \multirow{2}{*}{$\begin{array}{l}\text { Pro- } \\
\text { tumorigenic }\end{array}$} & 2002 & (11) \\
\hline & $\begin{array}{l}\text { NS subtype, non NS subtype, } \\
\text { MxC subtype }\end{array}$ & $\begin{array}{l}\text { CD3OL is expressed by MCs, and there is no difference in } \\
\text { MCs numbers between groups. }\end{array}$ & & 2001 & (12) \\
\hline \multirow{5}{*}{$\begin{array}{l}\text { Splenic Marginal } \\
\text { Zone Lymphoma } \\
\text { Primary } \\
\text { Cutaneous } \\
\text { Lymphoma (PCL) }\end{array}$} & $\begin{array}{l}\text { Grouped according to IIL score (Low risk, } \\
\text { intermediate risk, high risk) }\end{array}$ & MCs express CD4OL & \multirow{5}{*}{$\begin{array}{l}\text { Pro- } \\
\text { tumorigenic } \\
\text { Pro- } \\
\text { tumorigenic }\end{array}$} & 2014 & (14) \\
\hline & Mycosis fungoides (MF) & MC number and density higher in early stages of MF IA and & & 2016 & (15) \\
\hline & Stage IA-IB & $\mathrm{IB}$ & & & \\
\hline & Stage $\|A-\| B$ & & & & \\
\hline & Stage IVA & & & & \\
\hline \multirow[t]{3}{*}{$\begin{array}{l}\text { B cell Lymphoma } \\
\text { (BCL) }\end{array}$} & $\begin{array}{l}\text { DLBCL (Diffuse large B cell lymphoma) } \\
\text { Stage III-IV }\end{array}$ & Not mentioned & \multirow[t]{3}{*}{$\begin{array}{l}\text { Pro- } \\
\text { tumorigenic }\end{array}$} & 2016 & (17) \\
\hline & Stages Not mentioned & & & 2011 & (18) \\
\hline & $\begin{array}{l}\text { Samples from DLBCL, FL, Mantle cell } \\
\text { lymphoma, marginal zone B cell lymphoma }\end{array}$ & & & & \\
\hline \multirow[t]{2}{*}{$\begin{array}{l}\text { T cell Lymphoma } \\
\text { (TCL) }\end{array}$} & $\begin{array}{l}\text { Stages not mentioned, samples from } B C L \text {, } \\
\text { TCL }\end{array}$ & MC numbers were higher in TCL than $\mathrm{BCL}$ & \multirow[t]{2}{*}{$\begin{array}{l}\text { Pro- } \\
\text { tumorigenic }\end{array}$} & 2001 & (19) \\
\hline & $\begin{array}{l}\text { Stage not mentioned. } \\
\text { Samples from AITL (Angioimmunoblastic T } \\
\text { cell lymphoma), PCL }\end{array}$ & MC numbers were higher in AITL than PCL & & 2010 & (20) \\
\hline Leukemia & $\begin{array}{l}\text { CML Phases mentioned Chronic Phase, } \\
\text { Accelerated Phase and Blast Phase (ALLT, } \\
\text { AMLT) }\end{array}$ & $\begin{array}{l}\text { MC numbers were highest in AMLT (Acute myeloid leukemia } \\
\text { transformation stage) }\end{array}$ & $\begin{array}{l}\text { Pro- } \\
\text { tumorigenic }\end{array}$ & 2019 & (21) \\
\hline
\end{tabular}

Feng et al. considered IL-9 to be a key driver of tumor growth by which $\mathrm{T}_{\text {regs }}$ recruited and activated MCs to mediate immune suppression in the tumor region (18). The interplay of infiltrating $\mathrm{T}_{\text {regs }}$ and $\mathrm{MCs}$ in the tumor microenvironment therefore promotes the formation of tumor vessels, maintains the growth and metastasis of tumor in BCL.

Primary cutaneous lymphoma (PCL) is a non-Hodgkin's lymphoma also known as lympho-proliferative neoplasm of clonal B cell or $\mathrm{T}$ cell lymphoma largely associated with the skin (35). Studies have shown that there is an increased number of MCs present in both the cutaneous B cell lymphoma (CBCL) and cutaneous $\mathrm{T}$ cell lymphoma (CTCL) in peripheral rims of skin (15). In CTCL presence of MCs is correlated with reduced survival and increased malignancy in patients with progressive disease or advanced disease stage in Folliculotropic mycosis fungoides and Se'zary syndrome compared to stable patients or early disease stage in Mycosis fungoides (MF) (16). MCs are not only present in advanced stages of CTCL and CBCL, but have also extensively degranulated, which is much more noticeable in progressive form of these neoplasms, whereas more non-degranulated form of MCs are present in MF (15). In vitro study has shown that the supernatant of MCs obtained by treatment with calcium ionophore can induce the production of cytokines such as IL-17, IL-6 from tumor cells and increase the proliferation of primary CTCL cells (16). For the first time, Rabenhorst et al. have used a connective tissue-MCs depleted mouse model to demonstrate the delay in development of PCL thus highlighting the crucial role of MCs in controlling the tumor progression (16). Rabenhorst et al. also demonstrated that adding MC supernatant increased the proliferation of Sezary and CTCL cell lines whereas MC supernatant had no effect on the proliferation of SeAx and Mac2B CTCL cell lines when MC degranulation was inhibited by cromolyn (16). Therefore MCs play a pro-tumorigenic role in PCL, which is critical in the advanced stages of the disease and can be linked to disease severity.

$\mathrm{T}$ cell lymphomas (TCLs) account for the rare group of nonHodgkin's lymphoma group due to their low prevalence. Angioimmunoblastic TCL (AITL) is the uncommon aggressive subtype of the mature peripheral TCL that involves lymph node (36) and dysregulation of $\mathrm{T}$ cell immune response (37). The 
TABLE 2 | Experimental setup of the studies included in this review.

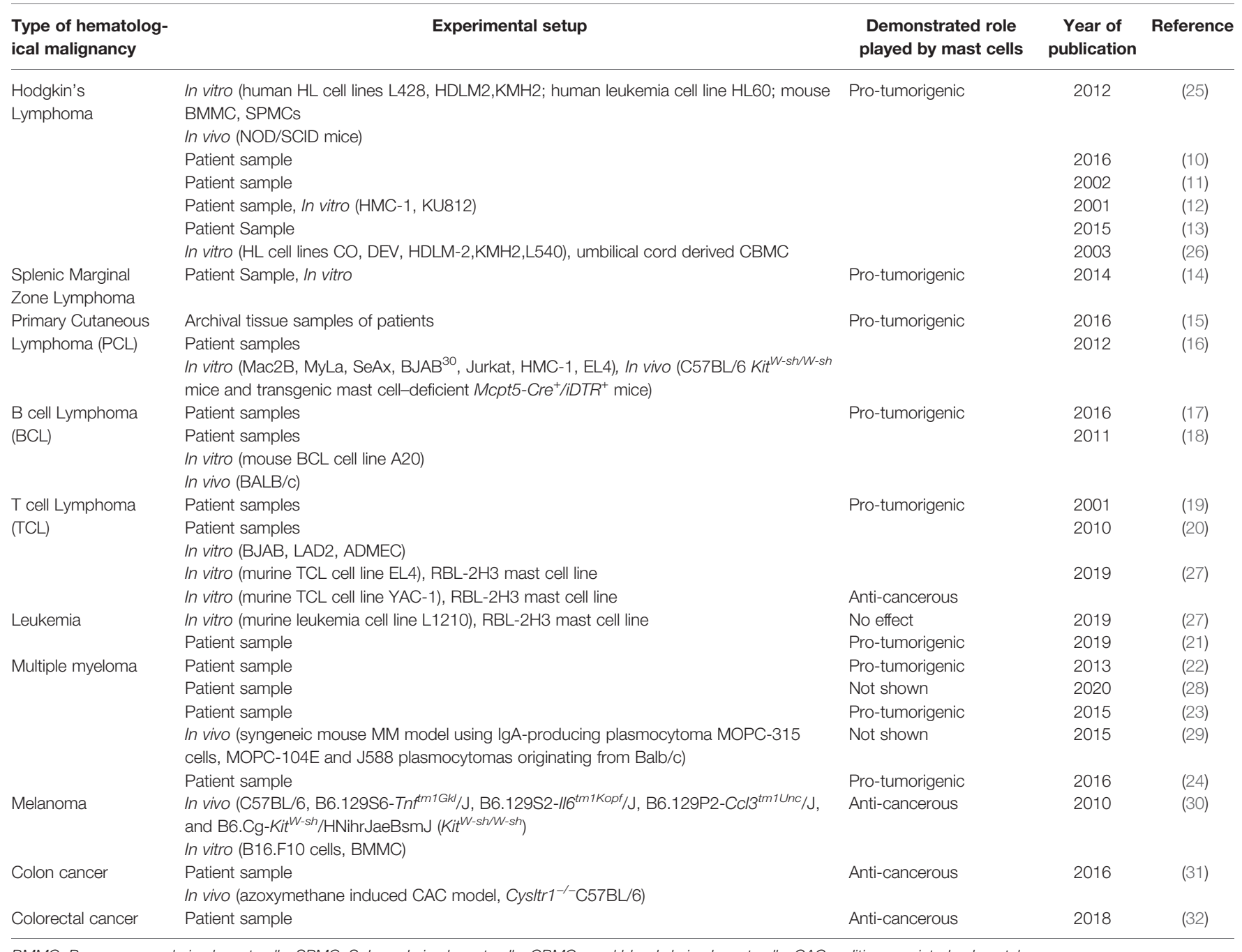

BMMC, Bone marrow-derived mast cells; SPMC, Spleen-derived mast cells; CBMC, cord blood-derived mast cells; CAC, colitis-associated colorectal cancer.

presence of micro-vessels with high endothelial venules is a prominent feature of AITL. There is strong correlation between MCs and number of blood vessels in TCL cases studied by Fukushima et al. Their study suggests that MCs are responsible for the angiogenesis and progression of AITL (19). Neoplastic follicular $\mathrm{T}_{\mathrm{h}}$ cells in AITL have been shown to produce CXCL-13, which is responsible for the accumulation of MCs strongly expressing IL-6 in AITL speculated to foster a pro-inflammatory microenvironment and deregulated angiogenesis (20). In addition to studies documenting the protumorigenic role of MCs in TCL, YAC-1 T cell lymphoma cells in direct contact with MCs or tumor cell supernatant when added to MCs was shown to induce degranulation of MCs (27). Interestingly, after co-treatment with histamine receptor antagonists and $\mathrm{MC}$ mediators, it was discovered that histamine receptors $\mathrm{H} 2$ and $\mathrm{H} 4$ are involved in inhibition of YAC-1 cell growth whereas histamine receptors $\mathrm{H} 1, \mathrm{H} 2$ and $\mathrm{H} 4$ are involved in enhancement of EL4 T cell lymphoma cell growth and overall regulation of $\beta$ catenin pathway (27). Furthermore, Rabenhorst et al. demonstrated that MCs are crucial for the progression of EL4 TCL tumors in vivo using an inducible mast cell deficiency mouse model Mcpt5-Cre/iDTR and Kit mutant mice. Increased proliferation of EL4 cells and release of proinflammatory cytokines on in vitro treatment with $\mathrm{MC}$ or BMMC supernatant was also observed (16). MCs exhibited a pro-tumorigenic role on the EL4 TCL cell line, but they exhibited an anti-cancerous role on the YAC-1 TCL cell line, implying that MCs may exist as picket cells in the lymphoma microenvironment and play a critical role in the suppression or advancement of tumorigenesis, depending on tumor characteristics and histamine receptor profile present on neoplastic cells (27).

\subsubsection{The Role of Mast Cells in Leukemia}

As discussed above there is a pro-inflammatory and procancerous role of MCs in various lymphomas with an exception in a $\mathrm{T}$ cell lymphoma. It was also demonstrated that MCs showed no effect on the proliferation of L1210 cell line which is a murine lymphocytic leukemia cell line in vitro (27). Similar to lymphomas, tryptase positive MCs were found to be abundant in the BM of chronic myeloid leukemia (CML) 
patients and increased MCs number in different stages of CML conformed to increased microvessel density and the advancement of CML to AML, which is the blast phase or the advanced stage (21). Interestingly, MCs count in acute lymphoblastic leukemia transformation (ALLT) stage was comparable to that of the healthy control group, implying that MCs control angiogenesis in the early stages of tumor development, whereas tumor cells drive growth and angiogenesis in later stages, and growth becomes MC-independent (21).

\subsubsection{The Role of Mast Cells in Myeloma}

Multiple myeloma (MM) is the malignancy of neoplastic plasma cells infiltrating the bone marrow. Similar to lymphomas and leukemias, patients with MM have an infiltration of tryptase positive MCs in their BM, associated with increased neovascularization and angiogenesis (22). Cytokines such as IL-6, VEGF, TNF- $\alpha$, B cell activating factor, and receptor activator of NF-kB ligand are elevated in MM (28). IL-6 is required for the survival and proliferation of normal immature $\mathrm{B}$ cells in the BM, and it has been identified as the key growth and survival factor for myeloma cells (28). Raised IL-6 levels can be caused by both myeloma precursor cells and the presence of MCs $(23,29)$. Increased MC density has also been linked to increased angiogenesis factors found in BM of MM patients (24). Therefore, MC can either directly or indirectly contribute to the progression of MM.

\subsection{Mast Cells and Conventional Cancer Therapy}

Conventional cancer therapy involves chemotherapy and radiotherapy which are principally used to kill the rapidly dividing tumor cells. According to Soule et al, MCs are resistant to cytotoxicity after radiation, and radiation has no effect on Kit and FcERI receptor expression. MCs degranulation is inhibited transiently and recovers within 24 hours after irradiation in human MCs, and MCs remain responsive to TLR-mediated signalling and produce cytokines (38). Westbury et al. observed a post-irradiation increase in the number of MCs (39). Radiation can also cause MC degranulation and the release of mediators like tryptase, as well as increase vascular permeability, which can lead to tissue injuries and fibrosis $(40,41)$. MCs may even be responsible for resistance to anti-PD1 therapy, which is linked to lower expression of HLA class1 in tumor cells, resulting in tumor escape from cytotoxic T cells (42). In prostate cancer, MCs can induce docetaxel resistance by phosphorylating p38 and radio-resistance by phosphorylating ATM, resulting in tumor cell survival and proliferation (43). Similarly, in inflammatory breast and pancreatic cancer, MCs have been implicated in tumor cell resistance to therapy and can also reduce the effect of antiangiogenic therapy (44-46). As a result, MCs have emerged as important candidate cells in the tumor microenvironment to be targeted for therapies.

\subsection{Various Strategies to Target Mast Cells as a Potential Therapeutic Approach}

As discussed in section 1.1, accumulation of MCs and their precise role in almost all hematological malignancies were evidently correlated with detrimental effects, poor prognosis, angiogenesis, tumor aggressiveness and metastasis as summarized in Figure 1. Increase in number of MCs in early stages is correlated as an angiogenic switch which triggers the tumor towards the malignant advancement (21). Myeloid derived suppressor cells (MDSCs), Tregs, NK cells have been extensively studied for their tumor mediated immunosuppressive activity and ability to impair immunotherapy response (47). The interplay between MCs and MDSCs can be speculated as a builder for inflammatory tumor microenvironment as MCs secrete CCL2 which can recruit MDSCs and subsequent IL-17 secretion recruits Tregs producing IL-9 which is required for maintenance of MCs contributing to the immunosuppressive microenvironment $(48,49)$ making MCs as an important target for a responsive immunotherapy.

MCs are an excellent candidate for targeted immunotherapy in the microenvironment of hematological malignancies because of their increased number, selective release of variety of mediators upon activation, and interaction with other cells. In this section we will discuss various strategies that could potentially help target MCs in the hematological tumor microenvironment.

\subsubsection{Strategies to Target Mast Cell Number}

c-KIT receptor is critical for the survival and development of MCs as MC depletion is shown in mouse models with c-KIT mutation (50). The targeting of c-KIT receptor is therefore one such strategy that may help to reduce the number of MCs in the tumor microenvironment of hematological malignancies. c-KIT is a tyrosine kinase receptor and can be targeted by numerous tyrosine kinase inhibitors used as anti-cancer drugs such as imatinib, sunitinib, sofrafenib, which bind and inhibit Bcr-abl fusion protein tyrosine kinase and are currently being used in CML (51), gastro-intestinal cancers and in thymic carcinoma (52). Other United States Food and Drug Administration (FDA) approved anti-cancer drugs that are studied to target c-kit include Amuvatinib, which has been clinically tested for lymphoma and small cell lung carcinomas, Axitinib, was clinically tested for advanced renal cell carcinoma, Cabozantinib, for prostate cancers and Dasatinib, for Chronic myeloid leukemia (52). A biologic inhibitor of c-KIT, KT0158, which is a humanized monoclonal antibody, has been shown to decrease MC degranulation and reduce MC numbers in a preclinical study (53).

In addition to c-KIT inhibitors, interestingly Fluvastatin, a statin drug used in the treatment of hypercholesterolemia not only suppresses IgE signaling in MCs but also induces apoptosis by inhibiting stem cell factor (SCF) induced survival signals in primary and in c-KIT mutated MCs (54). Consequently, the strategy to target the number of MCs would serve as an antiinflammatory approach with a potential to suppress neovascularization, leading to a considerable delay in the tumor growth prior to the initiation of angiogenic switch. This strategy could prove to be a rational and effective additional therapeutic strategy for lymphoid neoplasms negatively affected by MCs.

\subsubsection{Mast Cell Stabilization}

MCs release pre-formed mediators present within their granules and newly formed lipid mediators instantly upon activation and other newly synthesized mediators are released 3-12 hours later. 


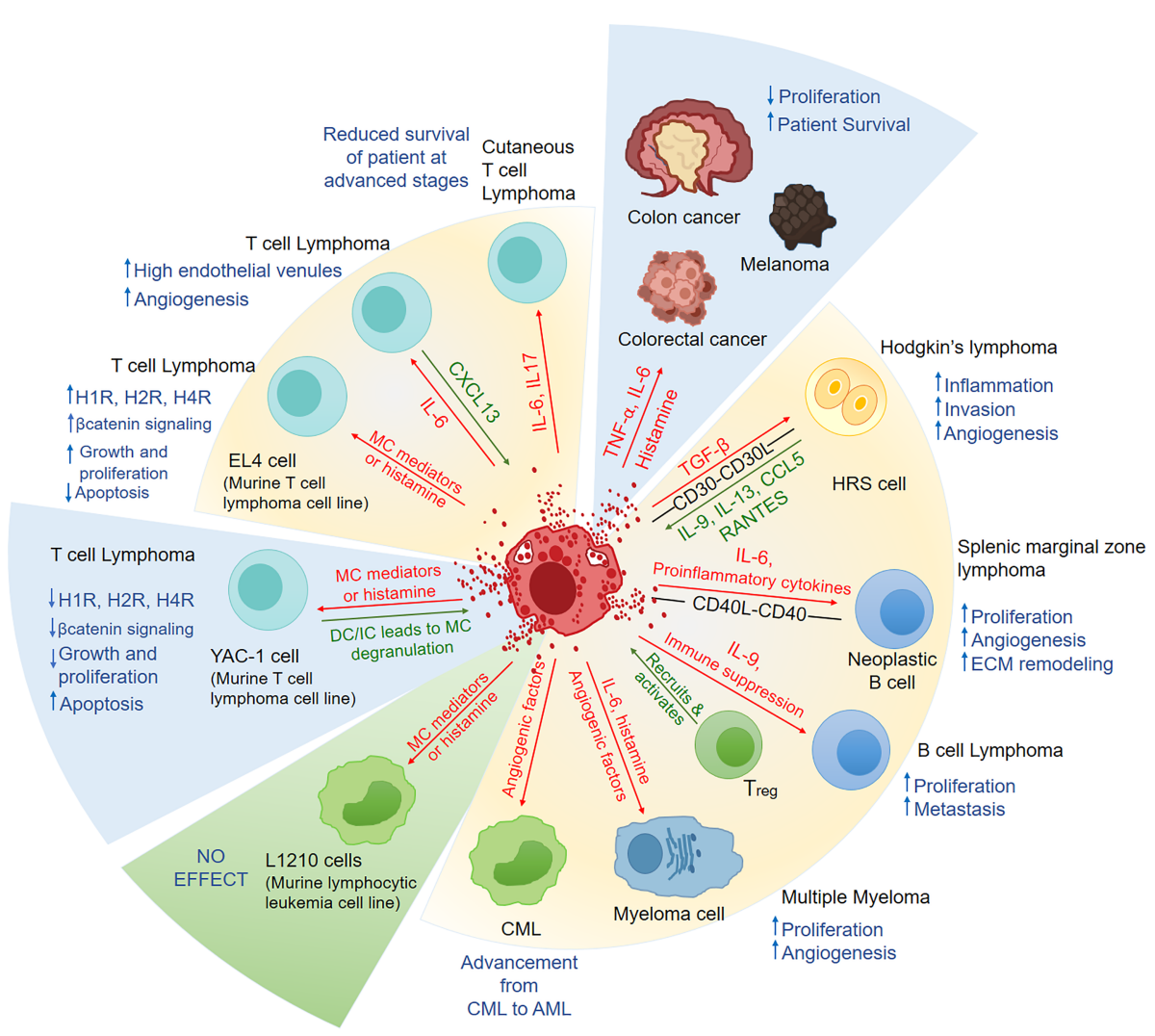

FIGURE 1 | A summary of the factors released by mast cells and their physiological response in hematological malignancies and solid cancers. In Hodgkin's lymphoma, splenic marginal zone lymphoma, B cell lymphoma, CML, T cell lymphoma, and myeloma MCs have been shown to play pro-tumorigenic role. In an in-vitro study, MCs had an anti-tumorigenic effect in T cell lymphoma but had no effect in murine lymphocytic leukemia. In some solid cancers, like colon cancer, melanoma and colorectal cancers, MCs have been shown to play anti-cancerous role. The factors released by MCs are represented by red arrows in this figure, while the factors/chemokines released by leukemia/lymphoma cells are represented by green arrows. Blue upwards arrow represents the increase and blue downwards arrow represents the decrease, as a result of the effect of MC on the malignancy. In the pie representation, blue slice represents the anti-cancerous role, green slice represents No effect and yellow represents pro-tumorigenic role played by MCs. MC, Mast cell; HRS, Hodgkin's and Reed-Sternberg cells; ECM, extracellular matrix; Treg, Regulatory T cells; CML, Chronic myeloid leukemia; AML, acute myeloid leukemia; H1R:, H1 Histamine Receptor; H2R, H2 Histamine Receptor; H4R, H4 Histamine Receptor; DC, Direct contact; IC, Indirect contact means MCs treated with tumor cell supernatant only.

T cell lymphoma cells have been shown to activate MCs to a similar extent as an allergen and show similar release of pre-stored mediators (27). These mediators are further responsible for the inflammation and angiogenic progression in lymphoid neoplasms or the rejection of tumors as seen in some solid cancers like breast cancer. Therefore, if it is not possible to eliminate MCs, we can think about stabilization of MCs. MC Stabilization is a method of preventing the release of histamine and other mediators involved in rogue actions by impeding degranulation.

Bortezomib, an NF-K $\beta$ inhibitor used to treat MM and other malignant hematological disorders, has been found to be minimally cytotoxic to MCs but can block MCs release, preventing fibrosis and vascularization in HL tumors in vivo. As a result, Bortezomib may be an interesting molecule to be used to kill malignant cells while simultaneously inactivating MCs in tumors, whereas Mizuno et al. claim that monotherapy may not work because the effect is transient (25).

Since histamine receptors are involved in responses to $\mathrm{MC}$ mediators, the use of $\mathrm{MC}$ antagonists may be helpful in reversing their response. Many MC stabilizers are now known to inhibit MC activation, such as $\mathrm{H} 1$ Histamine receptor antagonist Ketotifen, which is used to treat asthma and has been shown to suppress fibrosis (55). Azelastine, $\mathrm{H} 1$ receptor antagonist is a potent antiinflammatory molecule that also inhibits release of histamine, tryptase and IL-6 from MCs (56). To inhibit histamine receptors in TCL cell lines, Pyrilamine as an antagonist for H1 Histamine receptor, Ranitidine as an antagonist for $\mathrm{H} 2$ histamine receptor, and JNJ7777120 as an antagonist for H4 receptor have been used (27). Some Tyrosine kinase inhibitors which are anti-cancerous agents such as Nilotinib, Sunitinib, Ibrutinib have been shown to have antihistamine properties and can work as MC stabilizers (57-59). Not only chemical sources, but some natural sources of MC stabilizers such as flavonoids like luteolin, amentoflavone, bilobetin, quercetin $(60,61)$, phenols like curcumin (62) and alkaloids such as theanine present in green tea (63) have been shown to have antihistamine and MC stabilizing properties. It is therefore essential to identify and study how these stabilizers can be incorporated as add on therapeutic agents for the treatment of hematological malignancies. 


\subsubsection{Pre-Formed Mediators That Can Be Targeted or Incorporated in Cancer Therapies}

As discussed in the section 1.1, MCs identified in haematological malignancies are tryptase-positive and are capable of causing neovascularization by secreting tryptase and chymase, which are potent angiogenic factors (64). Gabexate mesylate (GM), Nafamostat mesylate (NM) are tryptase inhibitors. NM is 100 times more potent than GM which is used in the treatment of acute pancreatitis and has been tested on several human cancer cell lines and Tranilast is used in the treatment of bronchial asthma and has a potential anti-tumor activity (65). Therefore, these molecules may be incorporated into treatments. As a result, targeting tryptase released by $\mathrm{MC}$ in the tumor microenvironment will serve as an antiangiogenic strategy.

Although MCs have been shown to be involved in tumor progression, heparin, a MC mediator has been studied for its anti-cancerous role in many solid cancers (66). Heparin has been shown to attenuate metastasis in experimental cancer models possibly by inhibiting blood coagulation, inhibiting cancer cellplatelet and -endothelial interactions by selectin inhibition (67). It is therefore essential to study the role of heparin in hematological malignancies and thus strategies for including this molecule in cancer therapy.

Histamine is an important molecule that is pre-stored in MC granules and is the first molecule released when MCs are activated. Histamine has also been shown to be involved in cell proliferation, tumor development and embryonic development (68). The anti-cancerous properties of histamine in TCL have also been reported. Studies showed that histamine inhibits proliferation, decreases the survival and induces apoptosis in YAC-1 TCL cell line in vitro (27). Histamine dihydrochloride, a NOX2 inhibitor, targets MDSCs and improves immunemediated clearance of neoplastic cells, thereby improving the immunotherapy efficacy of PD1 checkpoint blockade (69). Because of its receptor expression on immune cells as well as on tumor cells, histamine becomes an important molecule that can be strategically included in anti-cancer therapy and can have a detrimental effect on tumor depending on the construction of tumor microenvironment, cell types present and the histamine receptor expression profile.

\subsubsection{Anti-Tumor Immune Responses of MCs}

Apart from the pro-tumorogenic role, MCs have been shown to have an anti-tumor role in some solid cancers such as melanoma, colon cancer, and colorectal cancer where MC presence in tumor is associated with improved patient survival (30-32), and also in a haematological neoplasm in vitro (27).

The tumor microenvironment contains sufficient chemokines and alternate molecules that can activate MCs. Chemotherapy and radiotherapy, as well as injury, cause dead and dying cells to release molecules known as alarmins or Danger-associated molecular patterns (DAMPs), which can activate MCs via TLRs and other receptors $(70,71)$. In hematological malignancies, alarmins such as IL-33 and Hsp-70 are commonly released, and cytokines such as IL- 1 have been found to activate MCs and cause the release of IL- 6 and TNF- $\alpha$, while chymase from MCs has been shown to degrade IL-33 and Hsp-70 due to their ability to cause inflammation $(70,72,73)$. Depending on the activation molecule and receptor activated on $\mathrm{MC}$, the anti-tumor mechanism involves recruiting immune effector cells such as NK cells and cytotoxic lymphocytes, which can eventually lead to tumor cell clearance or the development of anti-tumor immunity. Virus activated MCs have been shown to degranulate and produce type I and type III interferons, CXCL8, CXCR1, and TNF, which can recruit and activate IFN- $\gamma$ producing NK cells and NKT cells, allowing them to carry out cytotoxic actions which eliminate transformed cells (74-76). Interferon-stimulated chemokines have been found in tumors (32), therefore interferon-induced MC activation and NK cells recruitment may play a role in anti-tumor immunity.

Histamine, an important mediator released by MCs, is involved in the conservation of cytotoxicity receptors (NKp46, NKG2D) on NK cells in AML that are likely to be inhibited by phagocytes, and histamine prevents this inhibition by targeting $\mathrm{H} 2$ receptors on phagocytes (77). Histamine was used as a protector for cytotoxic lymphocytes and NK cells from phagocytes in a clinical study on AML where IL-2 was to be given as immunotherapy, which delayed relapse in patients and significantly improved the therapy (78). When activated, MCs also produce lipid mediators such as prostaglandins, leukotrienes, which are also involved in the recruitment of cytotoxic lymphocytes. As demonstrated in colorectal cancers that Leukotriene B4 derived from MC is in charge of recruiting and homing CD8+ $\mathrm{T}$ cells to the tumor site in order to generate anti-tumor immunity (79). As a result, MCs contribute chemokines, granule-associated and de novo synthesized mediators in tumor microenvironment, which may be important for immune regulation and anti-tumor responses.

To improve the recruitment of effector cells by MCs, innate immune activators such as TLR targeting immune-therapeutic molecules could be used. TLR-2 activated MCs have been shown to recruit NK cells and T cells in a melanoma model (30), whereas TLR-3 receptor activation on MCs increases $\mathrm{T}$ cell recruitment and regulates its functions (80). Therefore, TLR agonists can be combined with molecules that inhibit the release of pro-tumorigenic factors by MCs (as discussed in previous section), resulting in an effective anti-tumor response.

\section{CONCLUSION AND FUTURE PERSPECTIVES}

The presence of MCs has been increasingly recognized in human cancers. Pathological studies of MCs in human tissues have revealed contradictory results, explaining both a positive and a negative correlation between the number of MCs and prognosis in various cancers. The role of MCs in hematological malignancies has been the focus of this mini review as the role of MCs in tumorigenesis is of increasing interest following the use of anti-tumor agents that affect tumor growth by inhibiting factors known to be crucial to MC function.

MCs are found to be beneficial for the tumor growth in hematological neoplasms, as discussed in this review, with the 
exception of $\mathrm{T}$ cell lymphomas, where an in vitro study showed that MCs were detrimental to tumor cell growth. The role of MCs may be influenced by the stage of tumor development at which they infiltrate, their interaction with other cells, and the tumor microenvironment. MCs have been discussed to trigger the angiogenic switch in the tumors that helps to nourish the tumor and later on makes the tumor growth independent of MCs. MCs pro-tumorigenic effects are primarily mediated by angiogenic molecules secretion, tissue remodelling, tumor cell proliferation augmentation, and immunosuppression. Because MCs have the ability to influence cellular recruitment, proliferation, and functioning, they might be critical regulators of tumor microenvironment and, as a result tumor growth.

MCs can be activated by various molecules present in tumor microenvironment and are capable of secreting different mediators in response to different triggers. Sometimes they may only secrete cytokines without any release of pre-formed mediators. Also there is heterogeneity even in pre-stored mediators and their secretion is controlled by different secretion machinery (81). In such a scenario, it may be possible to specifically target and block secretion of proangiogenic factors and allow secretion of mediators which may have anti-tumor activities. Also it becomes important to understand the interactions of MCs with cancer stem cells or under hypoxic condition which is a hallmark of tumor microenvironment.

All of this tends to suggest that research into the role of MCs in hematological malignancies could have direct clinical implications in the use of targeted therapies, and that it should be investigated further using histopathological and appropriate multifaceted biological models. Some molecules or drugs that have been used for other purposes but can interfere with SCF-cKIT signaling could be repurposed, or some lysomotrophic drugs that cause granule permeabilization and eventually apoptosis of MCs could be geared at selectively limiting the number of MCs which may significantly reduce the inflammatory background that inevitably leads to aggravation and invasion of tumor cells. In

\section{REFERENCES}

1. Bispo JAB, Pinheiro PS, Kobetz EK. Epidemiology and Etiology of Leukemia and Lymphoma. Cold Spring Harbor Perspect Med (2020) 10:a034819. doi: 10.1101/cshperspect.a034819

2. Satyanarayana L, Asthana S, Labani SP. Childhood Cancer Incidence in India: A Review of Population-Based Cancer Registries. Indian Pediatr (2014) 51:218-20. doi: 10.1007/s13312-014-0377-0

3. Park SJ, Bejar R. Clonal Hematopoiesis in Cancer. Exp Hematol (2020) 83:105-12. doi: 10.1016/j.exphem.2020.02.001

4. Hopken UE, Rehm A. Targeting the Tumor Microenvironment of Leukemia and Lymphoma. Trends Cancer (2019) 5:351-64. doi: 10.1016/j.trecan. 2019.05.001

5. Gonzalez H, Hagerling C, Werb Z. Roles of the Immune System in Cancer: From Tumor Initiation to Metastatic Progression. Genes Dev (2018) 32:126784. doi: 10.1101/gad.314617.118

6. Elieh Ali Komi D, Wohrl S, Bielory L. Mast Cell Biology at Molecular Level: A Comprehensive Review. Clin Rev Allergy Immunol (2020) 58:342-65. doi: 10.1007/s12016-019-08769-2

7. Ghably J, Saleh H, Vyas H, Peiris E, Misra N, Krishnaswamy G. Paul Ehrlich's Mastzellen: A Historical Perspective of Relevant Developments in Mast Cell Biology. Methods Mol Biol (2015) 1220:3-10. doi: 10.1007/978-1-4939-1568-2_1 addition, we discussed some therapeutic strategies which are available or can be considered to inhibit the viability, accumulation and interfere with activation of MCs and their mediator release to enhance the anti-tumor response. In the context of hematological malignancies, one potential therapeutic mechanism could be to activate MCs using TLR-activators after chemotherapy/radiotherapy to boost the innate immune response and effector cell recruitment. TLR-activators may be used in conjunction with histamine. Antihistamines or MC stabilizers could be used in cases where there is increase in pro-tumorigenic or angiogenic molecules, for example histamine regulates myeloma cell growth. Interplay between MCs and Tregs is responsible for angiogenesis in BCL, therefore could be inhibited by reducing the numbers of MCs and Tregs. Thus, a decision about how to incorporate MCs in immunotherapy can be made based on the malignancy's microenvironment, chemokines, alarmins released, and the extent and type of histamine receptors expressed.

\section{AUTHOR CONTRIBUTIONS}

DM contributed to literature search, data curation and wrote the first draft of article. NP contributed to conception and design of the study, project administration and finalized the manuscript. All authors contributed to the article and approved the submitted version.

\section{FUNDING}

This study was supported by research grants from Department of Science and Technology (DST) - Science \& Engineering Board (SERB) Govt. of India (CRG/2019/003651) to NP. DM received senior research fellowship (2020-7400/SCR-BMS) from ICMR.
8. Kim HS, Kawakami Y, Kasakura K, Kawakami T. Recent Advances in Mast Cell Activation and Regulation. F1000Research (2020) 9:F1000 Faculty Rev196. doi: 10.12688/f1000research.22037.1

9. Ribatti D, Crivellato E. Mast Cells, Angiogenesis, and Tumour Growth. Biochim Biophys Acta (2012) 1822:2-8. doi: 10.1016/j.bbadis.2010.11.010

10. Nakayama S, Yokote T, Hiraoka N, Nishiwaki U, Hanafusa T, Nishimura Y, et al. Role of Mast Cells in Fibrosis of Classical Hodgkin Lymphoma. Int J Immunopathol Pharmacol (2016) 29:603-11. doi: 10.1177/0394632016644447

11. Molin D, Edstrom A, Glimelius I, Glimelius B, Nilsson G, Sundstrom C, et al. Mast Cell Infiltration Correlates With Poor Prognosis in Hodgkin's Lymphoma. $\mathrm{Br} \mathrm{J}$ Haematol (2002) 119:122-4. doi: 10.1046/j.1365-2141.2002.03768.x

12. Molin D, Fischer M, Xiang Z, Larsson U, Harvima I, Venge P, et al. Mast Cells Express Functional CD30 Ligand and Are the Predominant CD30L-Positive Cells in Hodgkin's Disease. Br J Haematol (2001) 114:616-23. doi: 10.1046/ j.1365-2141.2001.02977.x

13. Andersen MD, Kamper P, Nielsen PS, Bendix K, Riber-Hansen R, Steiniche T, et al. Tumour-Associated Mast Cells in Classical Hodgkin's Lymphoma: Correlation With Histological Subtype, Other Tumour-Infiltrating Inflammatory Cell Subsets and Outcome. Eur J Haematol (2016) 96:252-9. doi: 10.1111/ejh.12583

14. Franco G, Guarnotta C, Frossi B, Piccaluga PP, Boveri E, Gulino A, et al. Bone Marrow Stroma CD40 Expression Correlates With Inflammatory Mast Cell 
Infiltration and Disease Progression in Splenic Marginal Zone Lymphoma. Blood (2014) 123:1836-49. doi: 10.1182/blood-2013-04-497271

15. Eder J, Rogojanu R, Jerney W, Erhart F, Dohnal A, Kitzwogerer M, et al. Mast Cells Are Abundant in Primary Cutaneous T-Cell Lymphomas: Results From a Computer-Aided Quantitative Immunohistological Study. PloS One (2016) 11:e0163661. doi: 10.1371/journal.pone.0163661

16. Rabenhorst A, Schlaak M, Heukamp LC, Forster A, Theurich S, von BergweltBaildon M, et al. Mast Cells Play a Protumorigenic Role in Primary Cutaneous Lymphoma. Blood (2012) 120:2042-54. doi: 10.1182/blood-2012-03-415638

17. Marinaccio C, Ingravallo G, Gaudio F, Perrone T, Ruggieri S, Opinto G, et al. T Cells, Mast Cells and Microvascular Density in Diffuse Large B Cell Lymphoma. Clin Exp Med (2016) 16:301-6. doi: 10.1007/s10238-015-0354-5

18. Feng LL, Gao JM, Li PP, Wang X. IL-9 Contributes to Immunosuppression Mediated by Regulatory T Cells and Mast Cells in B-Cell Non-Hodgkin's Lymphoma. J Clin Immunol (2011) 31:1084-94. doi: 10.1007/s10875-0119584-9

19. Fukushima N, Satoh T, Sano M, Tokunaga O. Angiogenesis and Mast Cells in non-Hodgkin's Lymphoma: A Strong Correlation in Angioimmunoblastic TCell Lymphoma. Leukemia lymphoma (2001) 42:709-20. doi: 10.3109/ 10428190109099333

20. Tripodo C, Gri G, Piccaluga PP, Frossi B, Guarnotta C, Piconese S, et al. Mast Cells and Th17 Cells Contribute to the Lymphoma-Associated Pro-Inflammatory Microenvironment of Angioimmunoblastic T-Cell Lymphoma. Am J Pathol (2010) 177:792-802. doi: 10.2353/ajpath.2010.091286

21. Xu P, Zhang C, Wang Y, Wu H, Cheng S, Fan X, et al. Increased Number of Mast Cells in the Bone Marrow of Chronic Myeloid Leukemia may Herald the Pending Myeloid Transformation-The Mast Cell Is an Indicator of Myeloid Transformation. Trans Cancer Res (2019) 8:2121-9. doi: 10.21037/tcr.2019.09.29

22. Pappa CA, Tsirakis G, Roussou P, Xekalou A, Goulidaki N, Konsolas I, et al. Positive Correlation Between Bone Marrow Mast Cell Density and ISS Prognostic Index in Patients With Multiple Myeloma. Leukemia Res (2013) 37:1628-31. doi: 10.1016/j.leukres.2013.09.012

23. Devetzoglou M, Vyzoukaki R, Kokonozaki M, Xekalou A, Pappa CA, Papadopoulou A, et al. High Density of Tryptase-Positive Mast Cells in Patients With Multiple Myeloma: Correlation With Parameters of Disease Activity. Tumour biology: J Int Soc Oncodevelopmental Biol Med (2015) 36:8491-7. doi: 10.1007/s13277-015-3586-9

24. Vyzoukaki R, Tsirakis G, Pappa CA, Androulakis N, Kokonozaki M, Tzardi M, et al. Correlation of Mast Cell Density With Angiogenic Cytokines in Patients With Active Multiple Myeloma. Clin Ther (2016) 38:297-301. doi: 10.1016/j.clinthera.2015.11.022

25. Mizuno H, Nakayama T, Miyata Y, Saito S, Nishiwaki S, Nakao N, et al. Mast Cells Promote the Growth of Hodgkin's Lymphoma Cell Tumor by Modifying the Tumor Microenvironment That Can Be Perturbed by Bortezomib. Leukemia (2012) 26:2269-76. doi: 10.1038/leu.2012.81

26. Fischer M, Juremalm M, Olsson N, Backlin C, Sundstrom C, Nilsson K, et al. Expression of CCL5/RANTES by Hodgkin and Reed-Sternberg Cells and Its Possible Role in the Recruitment of Mast Cells Into Lymphomatous Tissue. Int J Cancer (2003) 107:197-201. doi: 10.1002/ijc.11370

27. Paudel S, Mehtani D, Puri N. Mast Cells may Differentially Regulate Growth of Lymphoid Neoplasms by Opposite Modulation of Histamine Receptors. Front Oncol (2019) 9:1280. doi: 10.3389/fonc.2019.01280

28. Jasrotia S, Gupta R, Sharma A, Halder A, Kumar L. Cytokine Profile in Multiple Myeloma. Cytokine (2020) 136:155271. doi: 10.1016/j.cyto. 2020.155271

29. Matthes T, Manfroi B, Zeller A, Dunand-Sauthier I, Bogen B, Huard B. Autocrine Amplification of Immature Myeloid Cells by IL-6 in Multiple Myeloma-Infiltrated Bone Marrow. Leukemia (2015) 29:1882-90. doi: 10.1038/leu.2015.145

30. Oldford SA, Haidl ID, Howatt MA, Leiva CA, Johnston B, Marshall JS. A Critical Role for Mast Cells and Mast Cell-Derived IL-6 in TLR2-Mediated Inhibition of Tumor Growth. J Immunol (2010) 185:7067-76. doi: 10.4049/ jimmunol.1001137

31. Mehdawi L, Osman J, Topi G, Sjolander A. High Tumor Mast Cell Density Is Associated With Longer Survival of Colon Cancer Patients. Acta Oncol (2016) 55:1434-42. doi: 10.1080/0284186X.2016.1198493

32. Mao Y, Feng Q, Zheng P, Yang L, Zhu D, Chang W, et al. Low Tumor Infiltrating Mast Cell Density Confers Prognostic Benefit and Reflects
Immunoactivation in Colorectal Cancer. Int J Cancer (2018) 143:2271-80. doi: $10.1002 / \mathrm{ijc} .31613$

33. Canioni D, Deau-Fischer B, Taupin P, Ribrag V, Delarue R, Bosq J, et al. Prognostic Significance of New Immunohistochemical Markers in Refractory Classical Hodgkin Lymphoma: A Study of 59 Cases. PloS One (2009) 4:e6341. doi: 10.1371/journal.pone.0006341

34. Piris MA, Onaindia A, Mollejo M. Splenic Marginal Zone Lymphoma. Best Pract Res Clin Haematol (2017) 30:56-64. doi: 10.1016/j.beha.2016.09.005

35. Willemze R, Cerroni L, Kempf W, Berti E, Facchetti F, Swerdlow SH, et al. The 2018 Update of the WHO-EORTC Classification for Primary Cutaneous Lymphomas. Blood (2019) 133:1703-14. doi: 10.1182/blood-2018-11-881268

36. Lunning MA, Vose JM. Angioimmunoblastic T-Cell Lymphoma: The ManyFaced Lymphoma. Blood (2017) 129:1095-102. doi: 10.1182/blood-2016-09692541

37. Iannitto E, Ferreri AJ, Minardi V, Tripodo C, Kreipe HH. Angioimmunoblastic TCell Lymphoma. Crit Rev Oncol/Hematol (2008) 68:264-71. doi: 10.1016/ j.critrevonc.2008.06.012

38. Soule BP, Brown JM, Kushnir-Sukhov NM, Simone NL, Mitchell JB, Metcalfe DD. Effects of Gamma Radiation on Fcepsilonri and TLR-Mediated Mast Cell Activation. J Immunol (2007) 179:3276-86. doi: 10.4049/jimmunol.179.5.3276

39. Westbury CB, Freeman A, Rashid M, Pearson A, Yarnold JR, Short SC. Changes in Mast Cell Number and Stem Cell Factor Expression in Human Skin After Radiotherapy for Breast Cancer. Radiotherapy Oncol: J Eur Soc Ther Radiol Oncol (2014) 111:206-11. doi: 10.1016/j.radonc.2014.02.020

40. Albrecht M, Muller K, Kohn FM, Meineke V, Mayerhofer A. Ionizing Radiation Induces Degranulation of Human Mast Cells and Release of Tryptase. Int J Radiat Biol (2007) 83:535-41. doi: 10.1080/09553000701444657

41. Park KR, Monsky WL, Lee CG, Song CH, Kim DH, Jain RK, et al. Mast Cells Contribute to Radiation-Induced Vascular Hyperpermeability. Radiat Res (2016) 185:182-9. doi: 10.1667/RR14190.1

42. Somasundaram R, Connelly T, Choi R, Choi H, Samarkina A, Li L, et al. Tumor-Infiltrating Mast Cells Are Associated With Resistance to Anti-PD-1 Therapy. Nat Commun (2021) 12:346. doi: 10.1038/s41467-020-20600-7

43. Xie H, Li C, Dang Q, Chang LS, Li L. Infiltrating Mast Cells Increase Prostate Cancer Chemotherapy and Radiotherapy Resistances via Modulation of P38/ P53/P21 and ATM Signals. Oncotarget (2016) 7:1341-53. doi: 10.18632/ oncotarget.6372

44. Reddy SM, Reuben A, Barua S, Jiang H, Zhang S, Wang L, et al. Poor Response to Neoadjuvant Chemotherapy Correlates With Mast Cell Infiltration in Inflammatory Breast Cancer. Cancer Immunol Res (2019) 7:1025-35. doi: 10.1158/2326-6066.CIR-18-0619

45. Porcelli L, Iacobazzi RM, Di Fonte R, Serrati S, Intini A, Solimando AG, et al. Cafs and TGF-Beta Signaling Activation by Mast Cells Contribute to Resistance to Gemcitabine/Nabpaclitaxel in Pancreatic Cancer. Cancers (2019) 11:cancers11030330. doi: 10.3390/cancers 11030330

46. Wroblewski M, Bauer R, Cubas Cordova M, Udonta F, Ben-Batalla I, Legler K, et al. Mast Cells Decrease Efficacy of Anti-Angiogenic Therapy by Secreting Matrix-Degrading Granzyme B. Nat Commun (2017) 8:269. doi: 10.1038/ s41467-017-00327-8

47. Draghiciu O, Lubbers J, Nijman HW, Daemen T. Myeloid Derived Suppressor Cells-an Overview of Combat Strategies to Increase Immunotherapy Efficacy. Oncoimmunology (2015) 4:e954829. doi: 10.4161/21624011.2014.954829

48. Danelli L, Frossi B, Pucillo CE. Mast Cell/MDSC a Liaison Immunosuppressive for Tumor Microenvironment. Oncoimmunology (2015) 4:e1001232. doi: 10.1080/2162402X.2014.1001232

49. Jachetti E, Cancila V, Rigoni A, Bongiovanni L, Cappetti B, Belmonte B, et al. Cross-Talk Between Myeloid-Derived Suppressor Cells and Mast Cells Mediates Tumor-Specific Immunosuppression in Prostate Cancer. Cancer Immunol Res (2018) 6:552-65. doi: 10.1158/2326-6066.CIR-17-0385

50. Grimbaldeston MA, Chen CC, Piliponsky AM, Tsai M, Tam SY, Galli SJ. Mast Cell-Deficient W-Sash C-Kit Mutant Kit W-Sh/W-Sh Mice as a Model for Investigating Mast Cell Biology In Vivo. Am J Pathol (2005) 167:835-48. doi: 10.1016/S0002-9440(10)62055-X

51. Sacha T. Imatinib in Chronic Myeloid Leukemia: An Overview. Mediterranean J Hematol Infect Dis (2014) 6:e2014007. doi: 10.4084/ MJHID.2014.007

52. Abbaspour Babaei M, Kamalidehghan B, Saleem M, Huri HZ, Ahmadipour F. Receptor Tyrosine Kinase (C-Kit) Inhibitors: A Potential Therapeutic Target 
in Cancer Cells. Drug Design Dev Ther (2016) 10:2443-59. doi: 10.2147/ DDDT.S89114

53. London CA, Gardner HL, Rippy S, Post G, La Perle K, Crew L, et al. KTN0158, a Humanized Anti-KIT Monoclonal Antibody, Demonstrates Biologic Activity Against Both Normal and Malignant Canine Mast Cells. Clin Cancer Res: an Off J Am Assoc Cancer Res (2017) 23:2565-74. doi: 10.1158/1078-0432.CCR-16-2152

54. Paez PA, Kolawole M, Taruselli MT, Ajith S, Dailey JM, Kee SA, et al. Fluvastatin Induces Apoptosis in Primary and Transformed Mast Cells. J Pharmacol Exp Ther (2020) 374:104-12. doi: 10.1124/jpet.119.264234

55. Gallant-Behm CL, Hildebrand KA, Hart DA. The Mast Cell Stabilizer Ketotifen Prevents Development of Excessive Skin Wound Contraction and Fibrosis in Red Duroc Pigs. Wound Repair Regen: Off Publ Wound Healing Soc [and] Eur Tissue Repair Soc (2008) 16:226-33. doi: 10.1111/j.1524-475X.2008.00363.x

56. Ciprandi G, Cosentino C, Milanese M, Tosca MA. Rapid Anti-Inflammatory Action of Azelastine Eyedrops for Ongoing Allergic Reactions. Ann Allergy Asthma Immunol: Off Publ Am Coll Allergy Asthma Immunol (2003) 90:4348. doi: 10.1016/S1081-1206(10)61829-7

57. El-Agamy DS. Anti-Allergic Effects of Nilotinib on Mast Cell-Mediated Anaphylaxis Like Reactions. Eur J Pharmacol (2012) 680:115-21. doi: 10.1016/j.ejphar.2012.01.039

58. Yamaki K, Yoshino S. Tyrosine Kinase Inhibitor Sunitinib Relieves Systemic and Oral Antigen-Induced Anaphylaxes in Mice. Allergy (2012) 67:114-22. doi: 10.1111/j.1398-9995.2011.02717.x

59. Chang BY, Huang MM, Francesco M, Chen J, Sokolove J, Magadala P, et al. The Bruton Tyrosine Kinase Inhibitor PCI-32765 Ameliorates Autoimmune Arthritis by Inhibition of Multiple Effector Cells. Arthritis Res Ther (2011) 13: R115. doi: $10.1186 /$ ar 3400

60. Kim HP, Park H, Son KH, Chang HW, Kang SS. Biochemical Pharmacology of Biflavonoids: Implications for Anti-Inflammatory Action. Arch Pharmacal Res (2008) 31:265-73. doi: 10.1007/s12272-001-1151-3

61. Weng Z, Zhang B, Asadi S, Sismanopoulos N, Butcher A, Fu X, et al. Quercetin Is More Effective Than Cromolyn in Blocking Human Mast Cell Cytokine Release and Inhibits Contact Dermatitis and Photosensitivity in Humans. PloS One (2012) 7:e33805. doi: 10.1371/journal.pone.0033805

62. Lee JH, Kim JW, Ko NY, Mun SH, Her E, Kim BK, et al. Curcumin, a Constituent of Curry, Suppresses Ige-Mediated Allergic Response and Mast Cell Activation at the Level of Syk. J Allergy Clin Immunol (2008) 121:122531. doi: 10.1016/j.jaci.2007.12.1160

63. Kim NH, Jeong HJ, Kim HM. Theanine Is a Candidate Amino Acid for Pharmacological Stabilization of Mast Cells. Amino Acids (2012) 42:1609-18. doi: 10.1007/s00726-011-0847-9

64. Ribatti D, Ranieri G. Tryptase, a Novel Angiogenic Factor Stored in Mast Cell Granules. Exp Cell Res (2015) 332:157-62. doi: 10.1016/j.yexcr.2014.11.014

65. Ammendola M, Leporini C, Marech I, Gadaleta CD, Scognamillo G, Sacco R, et al. Targeting Mast Cells Tryptase in Tumor Microenvironment: A Potential Antiangiogenetic Strategy. BioMed Res Int (2014) 2014:154702. doi: 10.1155/ 2014/154702

66. Borsig L. Heparin as an Inhibitor of Cancer Progression. Prog Mol Biol Trans Sci (2010) 93:335-49. doi: 10.1016/S1877-1173(10)93014-7

67. Niers TM, Klerk CP, DiNisio M, Van Noorden CJ, Buller HR, Reitsma PH, et al. Mechanisms of Heparin Induced Anti-Cancer Activity in Experimental Cancer Models. Crit Rev Oncol/Hematol (2007) 61:195-207. doi: 10.1016/ j.critrevonc.2006.07.007

68. Blaya B, Nicolau-Galmes F, Jangi SM, Ortega-Martinez I, Alonso-Tejerina E, Burgos-Bretones J, et al. Histamine and Histamine Receptor Antagonists in Cancer Biology. Inflamm Allergy Drug Targets (2010) 9:146-57. doi: 10.2174/ 187152810792231869

69. Grauers Wiktorin H, Nilsson MS, Kiffin R, Sander FE, Lenox B, Rydstrom A, et al. Histamine Targets Myeloid-Derived Suppressor Cells and Improves the Anti-Tumor Efficacy of PD-1/PD-L1 Checkpoint Blockade. Cancer Immunol immunotherapy: CII (2019) 68:163-74. doi: 10.1007/s00262-018-2253-6
70. Wang Y, Su H, Yan M, Zhang L, Tang J, Li Q, et al. Interleukin-33 Promotes Cell Survival via P38 MAPK-Mediated Interleukin-6 Gene Expression and Release in Pediatric AML. Front Immunol (2020) 11:595053. doi: 10.3389/ fimmu.2020.595053

71. Ashrafizadeh M, Farhood B, Eleojo Musa A, Taeb S, Najafi M. DamageAssociated Molecular Patterns in Tumor Radiotherapy. Int Immunopharmacol (2020) 86:106761. doi: 10.1016/j.intimp.2020.106761

72. Roy A, Ganesh G, Sippola H, Bolin S, Sawesi O, Dagalv A, et al. Mast Cell Chymase Degrades the Alarmins Heat Shock Protein 70, Biglycan, HMGB1, and Interleukin-33 (IL-33) and Limits Danger-Induced Inflammation. J Biol Chem (2014) 289:237-50. doi: 10.1074/jbc.M112.435156

73. Ronnberg E, Ghaib A, Ceriol C, Enoksson M, Arock M, Safholm J, et al. Divergent Effects of Acute and Prolonged Interleukin 33 Exposure on Mast Cell Ige-Mediated Functions. Front Immunol (2019) 10:1361. doi: 10.3389/ fimmu.2019.01361

74. Portales-Cervantes L, Haidl ID, Lee PW, Marshall JS. Virus-Infected Human Mast Cells Enhance Natural Killer Cell Functions. J Innate Immun (2017) 9:94-108. doi: 10.1159/000450576

75. St John AL, Rathore AP, Yap H, Ng ML, Metcalfe DD, Vasudevan SG, et al. Immune Surveillance by Mast Cells During Dengue Infection Promotes Natural Killer (NK) and NKT-Cell Recruitment and Viral Clearance. Proc Natl Acad Sci USA (2011) 108:9190-5. doi: 10.1073/pnas.1105079108

76. Burke SM, Issekutz TB, Mohan K, Lee PW, Shmulevitz M, Marshall JS. Human Mast Cell Activation With Virus-Associated Stimuli Leads to the Selective Chemotaxis of Natural Killer Cells by a CXCL8-Dependent Mechanism. Blood (2008) 111:5467-76. doi: 10.1182/blood-2007-10-118547

77. Romero AI, Thoren FB, Brune M, Hellstrand K. Nkp46 and NKG2D Receptor Expression in NK Cells With CD56dim and CD56bright Phenotype: Regulation by Histamine and Reactive Oxygen Species. Br J Haematol (2006) 132:91-8. doi: 10.1111/j.1365-2141.2005.05842.x

78. Brune M, Castaigne S, Catalano J, Gehlsen K, Ho AD, Hofmann WK, et al. Improved Leukemia-Free Survival After Postconsolidation Immunotherapy With Histamine Dihydrochloride and Interleukin-2 in Acute Myeloid Leukemia: Results of a Randomized Phase 3 Trial. Blood (2006) 108:88-96. doi: 10.1182/blood-2005-10-4073

79. Bodduluri SR, Mathis S, Maturu P, Krishnan E, Satpathy SR, Chilton PM, et al. Mast Cell-Dependent CD8(+) T-Cell Recruitment Mediates Immune Surveillance of Intestinal Tumors in Apc(Min/+) Mice. Cancer Immunol Res (2018) 6:332-47. doi: 10.1158/2326-6066.CIR-17-0424

80. Orinska Z, Bulanova E, Budagian V, Metz M, Maurer M, Bulfone-Paus S. TLR3-Induced Activation of Mast Cells Modulates CD8+ T-Cell Recruitment. Blood (2005) 106:978-87. doi: 10.1182/blood-2004-07-2656

81. Puri N, Roche PA. Mast Cells Possess Distinct Secretory Granule Subsets Whose Exocytosis Is Regulated by Different SNARE Isoforms. Proc Natl Acad Sci USA (2008) 105:2580-5. doi: 10.1073/pnas.0707854105

Conflict of Interest: The authors declare that the research was conducted in the absence of any commercial or financial relationships that could be construed as a potential conflict of interest.

Publisher's Note: All claims expressed in this article are solely those of the authors and do not necessarily represent those of their affiliated organizations, or those of the publisher, the editors and the reviewers. Any product that may be evaluated in this article, or claim that may be made by its manufacturer, is not guaranteed or endorsed by the publisher.

Copyright $\odot 2021$ Mehtani and Puri. This is an open-access article distributed under the terms of the Creative Commons Attribution License (CC BY). The use, distribution or reproduction in other forums is permitted, provided the original author $(s)$ and the copyright owner(s) are credited and that the original publication in this journal is cited, in accordance with accepted academic practice. No use, distribution or reproduction is permitted which does not comply with these terms. 